\title{
Ações, interações e transformações da Performance musical no confinamento
}

\author{
Sonia Ray \\ Universidade Federal de Goiás \\ soniaray@ufg.br \\ https://orcid.org/0000-0003-2843-7231
}

Resumo: A súbita mudança de comportamento e pensamento as quais o mundo foi obrigado a ser submeter desde março de 2020 em função da pandemia causada pelo surgimento do Coronavírus desencadeou novas formas de agir e interagir no universo da performance musical. No Brasil essa mudança significou também uma ressignificação do cotidiano do fazer musical abrindo a área para novas perspectivas. As ações em performance musical passaram a se dar exclusivamente a distância, obrigando músicos a se atualizarem com a tecnologia. As formas de interação se ampliaram passando a incluir criações coletivas no formato de 'mosaicos musicais' que uniram pessoas de várias partes do mundo. As transformações de hábitos na sociedade transformaram crenças pessoais bem como o cotidiano do estudo e prática do músico, o que não só abriu novas perspectivas para a performance musical, mas também novos questionamentos.

Palavras-chave: Performance musical no confinamento, Transformações na pandemia, Lives musicais, Mosaicos musicais, Perspectivas para a performance musical.

\section{Actions, interactions, and transformations of Musical performance during confinement}

\begin{abstract}
The sudden change in behavior and thought that the world has been forced to undergo since March 2020 due to the pandemic caused by the emergence of coronavirus has triggered new ways of acting and interacting in the universe of musical performance. In Brazil, this change also meant a resignification of the daily life of musical making opening the area to new perspectives. The actions in musical performance began happening exclusively in remote way, forcing musicians to update themselves with technology. The forms of interaction expanded to include collective creations in the format of 'musical mosaics' that brought together people from various parts of the world. The changes of habits in society transformed personal beliefs as well as the daily study and practice of the musician, which not only opened new perspectives for musical performance but also raised new questions.
\end{abstract}

Keywords: musical performance in confinement, Transformations in pandemic, Musical Lives, Musical mosaics, Perspectives for musical performance. 


\section{Introdução}

'Mudança' é uma palavra que o mundo teve que ressignificar desde o final da década de 1980, quando do surgimento da internet, sobretudo o universo das artes performáticas e seus processos criativos. Na performance musical, o impacto foi particularmente desafiador, impondo a inserção de recursos digitais em um processo de ensino e pesquisa tradicionalmente realizado de forma 'garimpeira', artesanal e presencial.

Ao longo dos últimos 30 anos ações artísticas e pedagógicas em performance musical gradualmente incluíram o uso de computadores. Partiu-se do computador como acessório para sua inclusão como protagonista, tornando inevitável sua utilização sem qualquer possibilidade de 'aceitar' que nem todo artista, professor ou aluno sentisse familiaridade com tal inclusão. Foi um processo chamado por muitos de 'exclusão digital', pois quem não aderiu foi excluído do acesso a oportunidades de trabalho, estudo, ampliação do conhecimento, aperfeiçoamento e sociabilização.

Contudo, sempre houve opções, ainda que escassas, de se fazer música e aprender música fora da internet, até março de 2020, quando a contaminação pelo Coronavírus surpreendeu o mundo e tornou impeditivo tudo que fosse presencial e não essencial para a manutenção imediata da vida: saúde, alimentação, transporte e atividades de suporte ao funcionamento dessas áreas.

Mais uma vez o mundo perdeu a chance de compreender o poder de gerar, manter e propagar vida, que é própria da arte. Esqueceu que sem arte as pessoas adoecem, sem arte surge o descontrole da condição psicológica de se manter uma rotina, sem arte situações psicológicas controláveis passam a quadros patológicos, sem arte interrompese o desenvolvimento do potencial de criação, e nos obrigamos a viver a realidade 'insuportável' de não poder mudar, criar ou intervir na sociedade. O famoso 'tubo de oxigênio' do senso comum, aquele cujos recursos não podem ser exauridos com riscos à vida, fica limitado ao tubo hospitalar e o homem adoece mais a cada dia que não pode respirar arte.

Assim, no mundo pandêmico, a 'arte dos espetáculos' a arte da 'performance musical' foi a primeira e ser interrompida e se tornou a última das preocupações dos 
legisladores e da própria sociedade. Falhamos nós, artistas, em trazer a sociedade para perto dos nossos 'criativos tubos de oxigênio' e mostrar a cada dona de casa o quão fundamental é a música na sua vida (como o 'agro' mostra todos os dias a importância do algodão, da soja, do trigo...). Não há aqui nenhum desmerecimento das áreas do agronegócio ou da medicina (Deus salve os guerreiros médicos desse país!), mas, não se pode tratar de modo tão discriminatório a distribuição de recursos para a arte e para a saúde com base no jargão de que 'tirar o tubo de oxigênio mata'. Não oferecer recursos de maneira igualitária também aniquila qualquer possibilidade da qualidade de vida humana, empresarial e social; é ter a arte como um corpo vegetando. Tal necessidade de maior atenção às áreas de artes foi recentemente admitida pelo presidente do CNPq, quando afirmou que "as empresas no Brasil não vão para frente sem ciências sociais, sem pesquisa em artes" [...] "arte e ciência têm tudo a ver e nós temos trabalhado pouco [isso] no nosso país", e acrescentou: "esta é uma área que nos interessa muito" (Vilela, 2020, áudio).

Mais atentos que os gestores dos fomentos, ficaram os grandes produtores de entretenimento que logo viram uma legião de milhões de pessoas confinadas e prontas para consumir. Uma programação 'gratuita' da TV aberta e das redes sociais patrocinadas passaram a confundir 'arte do entretenimento' com 'entreter com arte' o que implicou em ampliação dos recursos de poucos e a miséria de muitos.

As ações artísticas e pedagógicas sofreram o impacto de sua interrupção e posterior retorno em distanciamento. Artistas tiveram que descobrir novas formas de interagir com outras áreas e de sobreviver. As transformações internas e externas do artista da performance musical foram obrigatórias, com muitas perdas e algumas inovações que vieram para provocar, inspirar, preocupar, serem mescladas e, finalmente, vieram para ficar.

\section{Ações artísticas e pedagógicas}

Em março, início do confinamento, o uso da tecnologia na performance musical e em seu ensino já era intensamente promovido. Contudo, o protagonismo da tecnologia tornou-se obrigatório muito rapidamente, a ponto de instituições sem estrutura para oferecer acesso digital a seus alunos e professores tiveram que interromper suas 
atividades. Houve ainda aqueles que, mesmo com acesso, não conseguiram se familiarizar com processos remotos de fazer ou ensinar música.

Contudo, a corrida por atualização passou a ser de todos. Artistas tentando reestabelecer sua renda, instituições tentando manter seu funcionamento a partir de cursos relâmpago de capacitação de professores, estudantes descobrindo como acessar seus mentores para decidirem como seguir. Em semanas surgiram propostas de ações artísticas na rede de alcance mundial (World Wide Web) bem como de caminhos para realizá-las (cursos, palestras, aulas oferecidas por fabricantes de aplicativos atualizados), em plataformas cada vez mais 'amigáveis' para a manipulação dos 'não especialistas' em tecnologia.

$\mathrm{Na}$ medida em que se percebeu que a quarentena seria longa, as performances musicais passaram a se dar exclusivamente a distância, obrigando até os músicos mais reclusos a se ambientarem com a tecnologia. As formas de interação artística se ampliaram passando a incluir colaborações, inicialmente em duetos, e rapidamente se expandiu para grandes grupos em formato de 'mosaicos musicais' que uniram pessoas de várias partes do país e do mundo. Um dos primeiros aplicativos explorados foi o ' $A$ Capella', que permite gravações de vídeo em colaboração de até 4 músicos por até 30 segundos de forma gratuita (esses limites são liberados quando o usuário assina o serviço do aplicativo). Muitos músicos testaram fazer duos, trios e quartetos gravando sozinhos partes diferentes de uma peça. Começou como uma grande brincadeira, um passatempo de confinamento. Logo passou a ser estratégia de trabalho remoto, pois estes tipos de gravação permitiram justificar o trabalho de músicos que estavam impossibilitados de atuar em suas orquestras, corais, escolas e bandas.

As instituições passaram então a promover os mosaicos musicais como uma espécie de prestação de contas à sociedade, justificando o salário dos afortunados que conseguiram manter seus empregos (notadamente orquestras, bandas e corais). Contudo, muitos não conseguiram manter suas fontes de renda e passaram a sofrer a concorrência da mídia patrocinada na internet. Uma verdadeira explosão de ofertas de lives de artistas famosos passou a dominar o cenário artístico na TV aberta e no YouTube levando alegria e comodidade para milhares de pessoas confinadas, mas ao mesmo tempo, propagando a aparente simplicidade em realizar tal empreitada. 
O país passou a ver transmissões com produção profissional feita com recursos expressivos acessíveis à 'um click' de distância, mas com a mensagem de que estávamos todos na mesma situação: presos em casa na limitação de convivência dos que moravam no mesmo domicílio. A primeira dessas grandiosas transmissões foi o show da cantora Ivete Sangalo (vestida com seu pijama de bolinhas e com patrocínio da Globo e Vivo ${ }^{1}$ ) na sala de sua casa, somente com a presença do marido e do filho. Nenhum problema com relação a uma artista que ganha bem para se apresentar no confinamento, a artista poder ganhar bem para se apresentar no confinamento, porém, a ideia de que artistas estavam bem porque podiam se dar ao luxo de ficar em casa, relaxando, cantando e divertindo as pessoas não ajudou a manter os milhares de empregos perdidos por artistas que não obtiveram patrocínio para realizarem suas performances. Depois da transmissão de Ivete, seguiram-se muitas outras, entre elas a de Marília Mendonça, Caetano Veloso, Milton Nascimento muitas duplas do chamado 'novo sertanejo' - todas elas, superproduções com tratamentos de áudio e vídeo que um artista sem patrocínio jamais poderia fazer. Ainda que as lives tenham sido veículos de campanhas de solidariedade, não se tem notícia de que alguma tenha ajudado músicos preteridos de trabalhar em função da pandemia. Desta maneira consolidou-se, de forma intensa, o rito do capitalismo globalizado onde dinheiro gera dinheiro e o desemprego obriga profissionais (sobretudo artistas) a buscarem outras formas de sobreviver com trabalhos improvisados fora de sua área de atuação.

Simultaneamente, de forma a sobreviver artisticamente, os agentes do ensino instituições, professores e alunos, buscaram uma maneira de manter suas atividades. $\mathrm{O}$ ensino remoto foi o grande desafio do início da quarentena e seu constante aperfeiçoamento, uma batalha contínua e atual. Nesse desafio muitos profissionais ligados a área não tiveram novas oportunidades de trabalho, estudo, ampliação de conhecimento, aperfeiçoamento e sociabilização, por não se adequarem a chamada “inclusão digital”, ocorrendo situação inversa, ou seja, a "exclusão digital

Sem acesso a um sinal de internet de qualidade razoável, não havia professores repassarem aos seus alunos, um ensino remoto de qualidade (síncrono e assíncrono). Se o que é desconhecido já traz algum receio natural, a resistência em aprender a lidar com

\footnotetext{
${ }^{1}$ https://gshow.globo.com/Famosos/fique-em-casa/noticia/ivete-sangalo-faz-live-em-casa-de-pijamasejam-bem-vindos.ghtml
} 
procedimentos didáticos diferentes em tempo mínimo, elevou os níveis de ansiedade e gerou casos de desistência do ano letivo em todos os níveis, tanto por parte dos alunos, como por parte de alguns professores. Os que encararam a batalha de retomar o primeiro semestre de 2020 se viram em situações distintas, em diferentes níveis de ensino.

Depoimentos de diretores e coordenadores do ensino fundamental e médio atestam, por um lado, maior dependência de alunos de tutorias para desenvolverem suas tarefas. Por outro, evidenciou-se grande empenho de professores em se manterem próximos aos alunos, revelando uma afetividade tão direta que transpôs a sala de aula, especialmente fora dos grandes centros urbanos. Já no ensino em nível superior e na pós-graduação, cresceu a independência dos alunos com relação a realização de suas atividades, já que as aulas e demais ações pedagógicas passaram a ser $100 \%$ on-line, quase que proporcionalmente ao aumento de resistência de parte de professores, que se mantiveram reticentes em alterar seus procedimentos didáticos, sobretudo no ensino de performance musical.

Aulas de performance musical são tradicionalmente feitas de forma presencial, e a relação professor-aluno é muito próxima, não raro mais próxima que a relação do aluno com sua família. O trabalho didático envolve, além de demonstração de técnica instrumental/vocal, aspectos de uso do corpo, processos imitativos e o indissociável aspecto sonoro: ouvir o som em tempo real e melhorar a execução via exploração da produção sonora.

O grande vilão dos processos didáticos de performance musical em 2020 não foi o confinamento determinado pela situação de pandemia, mas sim a falta de estrutura física e humana do país para oferecer conexões digitais apropriadas para interação em tempo real de som e imagem que permitisse melhor qualidade nas atividades de performance musical. Consequentemente, as instituições de ensino se viram obrigadas a resolver a questão com os recursos que lhes foram possíveis. Duas questões se destacam nesse cenário, que apresento a seguir, de forma breve.

Por um lado, as dificuldades nas aulas de instrumento individual, canto e música de câmara se deram pela mútua inexperiência de professores a alunos em lidar com o ensino remoto. Os recursos físicos não ajudavam (equipamentos sem programas adequados instalados e conexão de internet ineficiente), entretanto, foram os recursos humanos que 
mais dificultaram o processo. Na crença de que "nada substitui o ensino presencial em performance musical', muitos se recusaram a tentar fazê-lo ou o fizeram com clara descrença em possíveis resultados positivos. Consequentemente uma grande insegurança foi instaurada no processo: de um lado professores ensinando sem esperarem o devido retorno por parte do aluno, de outro lado, o aluno frustrado e sem orientação precisa de como continuar se desenvolvendo com os recursos disponíveis.

O mais surpreendente, contudo, foi a falta de criatividade de muitos docentesartistas (em muitos casos artistas de grande reconhecimento na área) que passaram a negar qualquer eficiência em ensinar com material de conexão de baixa, deixando transparecer, na verdade, suas inseguranças com processos experimentais com os quais não estavam familiarizados. Há muito o que se ensinar/aprender sobre a performance musical além da tradicional aula presencial. Ela pode ser trabalhada não apenas na troca de gravações curtas entre professor e aluno, ou em exemplificações realizadas nas ligações de vídeo de péssima qualidade. São indispensáveis as reflexões sobre estilo, articulação, uso do corpo, auto percepções entre outros aspectos, além da consideração fundamental de que este é um momento que o professor tem muito a ensinar ao músico prático sobre superação de limitações externas.

Por outro lado, foram observadas iniciativas de superação e criatividade em ações de professores e alunos em vários níveis e áreas de ensino de música, incluindo a performance musical. Muitas entrevistas na mídia séria (notícias verídicas) mostraram professores atuantes em áreas periféricas sem acesso a internet se reinventando para fazer chegar de forma impressa, as tarefas de seus alunos mais carentes. No ensino superior, aulas de performance musical (música de câmara, instrumento e canto) usaram o recurso de mosaicos musicais para treinar a percepção timbrística, de afinação e ritmo dos alunos no processo de gravação dos áudios e vídeos. Resultados trabalhados em edições serviram para revelar aos participantes os limites entre preparação, realização e avaliação da performance musical, tornando esse aprendizado um adicional ao estudo tradicional, ao invés de substitui-lo. Ganharam professores e alunos que mergulharam nas tentativas de contornar o momento e, no caso da universidade, ampliaram-se as pesquisas e projetos de extensão, oferecendo entretenimento com arte à comunidade. 


\section{Interações com pares e com outras áreas}

Se, por um lado, a situação de confinamento imposta pela pandemia interrompeu bruscamente o cotidiano dos processos criativos em performance musical, por outro, incentivou formas de interação questionadoras e inovadoras. Registros de performance musical coletiva se ampliaram, passando a incluir 'mosaicos musicais' unindo pessoas de várias partes do Brasil e do mundo.

Questionamento é o combustível que impulsiona a criação e leva o artista a ações criadoras. Nesse sentido, qualquer questionamento, positivo ou negativo, carrega em si o potencial de gerar caminhos férteis para a performance musical. A não aceitação imediata do fazer musical via aplicativos de internet levou artistas mais familiarizados com o mundo digital a promoverem cursos e palestras destinados a inclusão daqueles menos confortáveis com o processo. Tal movimento significou fonte de renda para muitos artistas, prejudicados pela suspensão dos espetáculos com público presencial, que passaram a atuar como professores online.

Do ponto de vista da inovação, ao longo de 2020 muito se investiu na manutenção do fazer artístico como resistência à falta de renda, risco de depressão em função do confinamento, afastamento do público, afastamento dos locais de ensino e das relações humanas presenciais. No processo de inovar a performance musical, pouco se mostrou de fato 'novo' mas as abordagens no processo foram transformadas. Mosaicos musicais não foram inventados em 2020, porém, o processo de elaboração e realização de tais colaborações (ensaios, performances e gravações) tiveram que ser reformulados para aconteceram 100\% à distância. Em 25 anos de existência da internet pública nunca se havia explorado tanto as possibilidades de interação remota no fazer musical.

Expertos em tecnologia audiovisual tiveram que se adaptar ao contato direto com o artista, e não com a equipe de produção, pois no cotidiano do confinamento as relações ficaram bem menos intermediadas por falta de recursos ou de hábito. Muitos artistas tiveram que aprender a fazer o trabalho de produção, estudando tutoriais e aprendendo no dia-a-dia a linguagem dos tecnólogos. O pesquisador Silvio Meira (2020), acredita que as pessoas aprendem a usar a internet tentando, errando e tentando de novo. Assim, aqueles mais persistentes aprenderam mais e geraram mais conteúdos interativos em canais de YouTube, Instagram e Facebook do que aqueles que giraram em torno do 
tradicional (concertos, entrevistas e aulas), criando performances musicais e mesas redondas ao vivo em transmissão simultânea para vários canais, o que antes de 2020 só se via acontecer em transmissões profissionais.

A colaboração entre músicos de partes diferentes do mundo parece ter sido o grande marco dos mosaicos musicais e a tecnologia proporcionou a ampliação da visão de criação coletiva mundial em performance musical. O confinamento obrigou os artistas a produzirem música de forma isolada, ocorreram muitos protestos e manifestações de união em torno de causas de forte impacto na sociedade (a exemplo dos movimentos antirracistas e humanitários). Assim, diversos mosaicos foram produzidos tematicamente, unindo instrumentistas, cantores, regentes, produtores e artistas do palco como uma espécie de ação artística para o bem de todos. Como exemplo tivemos os mosaicos de vozes mistas (Coro da OSESP, 2020²) de um único instrumento (IOBS, 202033; Gravidade, 20204), de grupos de dança (Festival Quarentena, 20205\% Operà de Paris, $\left.2020^{6}\right)$, de orquestras (OSESP, $2020^{7}$ ), entre outros.

Estas colaborações provocaram um grande intercâmbio entre profissionais de áreas que se mostraram mais próximas do que poderíamos imaginar. Profissionais das artes (visuais, cênicas, dança e música), artistas, técnicos e pesquisadores se viram na necessidade de se unirem para sobreviver. Neste processo, novas funções foram se revelando junto com a necessidade de passarmos o período indefinido de restrições básicas, com sanidade mental. Não é coincidência que estudos de concentração na performance musical tenham ganhado uma publicação (RAY; ZANINI; AGUIAR, 2020), produção finalizada ao longo da pandemia e inspirada nos erros e acertos dos próprios autores dos textos, que são resultantes de pesquisas concluídas.

Artistas foram se capacitando, se adaptando e possibilidades de criação com uso de recursos externos à música se destacaram. Produções inovaram mesclando música e

\footnotetext{
${ }^{2}$ CORO DA OSESP, 2020. Suíte Nordestina. https://www.facebook.com/osesp/posts/3040028142712452.

${ }^{3}$ IOBS, 2020.International Online Bass Summit. https://www.basssummit.org/.

${ }^{4}$ GRAVIDADE, 2020. Telefone sem Fio-1 <https://www.youtube.com/watch?v=zZeWxJZqqrM>;

Telefone sem fio-2 $<$ https://youtu.be/q_rf0OWJGow $>$.

${ }^{5}$ FESTIVAL QUARENTENA, 2020.

https://www.facebook.com/permalink.php?id=148877978462676\&story_fbid=3469104106440030.

6 OPERA DE PARIS, 2020. https://www.dailysabah.com/arts/performing-arts/paris-opera-movesperformance-to-digital-platform-as-covid-keeps-theaters-closed.

${ }^{7}$ OSESP, 2020. Trenzinho do Caipira. https://www.youtube.com/watch?v=KTKVgaY56NI.
} 
museu $\left(\right.$ Mawaca $^{8}$ ), música e tradições populares (Acervo Maracá ${ }^{9}$ ), música e tecnologia digital, além da exploração da relação entre música e aspectos sociais nos debates online. Em performance musical e tecnologia apresento uma colaboração que está em andamento com o compositor Jonatas Manzoli que assim me descreveu sua proposta: "a ideia do processo é começar com um texto... escrevi um poema que envio para você. Gostaria de ouvir a sua leitura. Tanto falada, quanto no contrabaixo. Alguma improvisação. O que você achar que conversa com o poema." ${ }^{10}$ Como o compositor tem trabalho de longa data com tecnologia, a proposta se chama "carta sonora" e já apresentou vários resultados de colaborações com esta mesclagem. A Carta Sonora Ray-Manzoli deve sair em breve!

\section{Transformações internas e externas}

Os meses de confinamento em 2020 mudaram o comportamento das pessoas em sua intimidade e atuação profissional, bem como o olhar de cada indivíduo sobre como o mundo o vê. Com a intimidade do lar e as atividades específicas de trabalho unidas, tais mudanças levaram a transformações sob duas perspectivas: pessoal e profissional, particularmente dos que atuam em performance musical. Estudar um instrumento ou praticar canto em casa nem sempre é possível, pois a invasão sonora pode ser um tanto incômoda para vizinhos e familiares. Há que se lembrar que estudar é diferente de realizar performances. Há estudos técnicos que muito frequentemente exigem repetições e tentativas de modificação do texto musical que são comuns a quem os pratica e não trazem associações a apreciação musical para leigos. A adaptação do estudo/trabalho em casa encontrou caminhos com muita negociação e, em alguns casos, levou a desistência temporária do músico por se aperfeiçoar.

A realidade do cotidiano de muitos músicos passou a ser relatada em entrevistas e depoimentos nas várias transmissões em canais da internet chamando a atenção para uma questão há muito debatida por pesquisadores da área, qual seja: a importância dos registros de relatos de experiências com a prática e pedagogia da performance musical (BORÉM; RAY, 2011 e RAY, 2019).

\footnotetext{
${ }^{8}$ MAWACA. Kaprolin. https://www.youtube.com/watch?v=eZB2heUWY5w.

${ }^{9}$ ACERVO MARACÁ. https://www.youtube.com/watch?v=MAO1qomjd-I.

${ }^{10}$ Correspondência via WhatsApp entre os artistas em 27 nov. 2020.
} 
Muitos relatos deixaram expostas inseguranças, questionamentos, emoções e soluções encontradas por músicos atuantes sobre como estudar/trabalhar durante o período de confinamento. Na série de 200 Lives (Ray, 2020), 150 entrevistados de todo o Brasil e de outros 9 países (EUA, França, Noruega, Alemanha, Portugal, Inglaterra, Suíça, Índia e Argentina) relataram suas experiências com o objetivo de levar o sentimento de empatia aos internautas participantes. As abordagens ajudaram a dar concretude a possibilidade de parar, retomar, recomeçar, mudar o 'como' fazer em um universo aparentemente tão individual, mas que se mostrou com inúmeras similaridades nos apontamentos dos relatos. Os registros não só abriram novas perspectivas para a performance musical, mas também novos questionamentos sobre como prepará-la e realizá-la remotamente.

A precariedade e morosidade na liberação de recursos no Brasil para desenvolvimento de pesquisas sobre questões emergenciais não relacionadas à saúde não permitiu que novos projetos em âmbito nacional fossem gerados, financiados e realizados nos últimos 10 meses. A necessária análise da concepção e produção artística em período de confinamento ficou concentrada em atitudes individuais de pesquisadores, depoimentos informais ou em coletas de dados de instituições de ensino. Todas essas atitudes são fundamentais para que se possa compreender em curto/médio prazo as transformações pela qual a produção artística passa neste momento. Do outro lado dessa realidade estão grupos de pesquisadores europeus, a exemplo do Centre for Performance Science do Royal College of Music, que sedia projetos de âmbito nacional investigando as formas de interações e as transformações nas práticas de performance musical em estudantes e profissionais, bem como elas estão afetando a formação e atuação desses artistas. Um destes projetos tem o objetivo de compreender o sentido e a natureza das conexões entre solidão, isolamento social e saúde mental no momento atual (PERKINS, et alli, 2020).

No Brasil, a insistência do poder público em minimizar a seriedade da pandemia retardou pesquisas na área de infectologia e epidemiologia e distanciou artistas dos grupos prioritários de acesso a recursos, colocando a arte como menos importante para a sociedade ao invés de tentar compreender melhor como a arte melhora uma sociedade adoecida. Uma exceção foi a aprovação da Lei Aldir Blanc (PL1075/2020) que contemplou profissionais da cultura com um auxílio emergencial, que, se não resolveu, 
pelo menos minimizou a carência da área face a clara incompetência das autoridades de educação e cultura do país em apresentarem soluções eficientes aos artistas e demais profissionais de ensino e pesquisa em artes.

\section{Considerações finais}

Ainda que a proposta deste texto tenha sido tripartite (ações, interações e transformações), a discussão sobre cada parte deixa clara a inter-relação entre elas, parte inerente ao processo de preparação e realização da performance musical. O que não foi novo foi pelo menos inovador nos processos de ação, interação e transformação, uma vez que a sociedade contemporânea ainda não havia vivido uma situação pandêmica tão grave. O sentido inovador se deu nas soluções encontradas, notadamente ligada a conexão via rede de alcance mundial (world wide web), com uso de vários dispositivos móveis e com ampla adaptação de aplicativos às necessidades do artista da performance musical que se viu confinado, sem renda e sem perspectivas, de maneira abrupta, no início de 2020.

No processo de descobrir novas formas de interagir, o artista da performance musical descobriu também formas de explorar outras áreas do conhecimento para unir capacidades pelo bem comum. Nessa luta por sobrevivência, a manutenção da saúde mental recebeu atenção especial de pesquisas, sobretudo no exterior onde os investimentos possibilitaram aos pesquisadores investigar o momento presente.

As ações artísticas e pedagógicas interagiram com as transformações de comportamento da sociedade. As criações coletivas no formato de 'mosaicos musicais' conseguiram unir profissionais das artes e da produção artística em ações que uniram músicos, técnicos, pesquisadores de várias partes do mundo e levaram a milhares de pessoas, entretenimento para ajudar a sociedade a ficar confinada. Ainda que tenha havido grandes injustiças na geração/distribuição de recursos para a classe artística, os produtos gerados de colaborações artísticas foram de inegável contribuição para envolvimento da sociedade com a produção artística.

Por fim, novas perspectivas se abriram ao longo desses 10 meses de confinamento, de forma que é plausível esperar que a comunidade de artistas da performance musical incorpore mudanças (como o fazer artístico de forma remota) em seus cotidianos, mais 
mudanças, inovações e transformações. Neste momento, o recém anúncio de aprovação de vacinas que combaterão o coronavírus começam a restaurar a esperança e ampliar as perspectivas para artistas e para o mundo. Assim, novos questionamentos surgirão em breve e espera-se que mais discussões e pesquisas sejam realizadas, principalmente aquelas que enfoquem a performance em situações adversas, como a que estamos tendo nessa pandemia.

\section{Referências}

BORÉM, Fausto; RAY, Sonia. Pesquisa em performance musical no Brasil no século XXI: problemas, tendências e alternativas. In: SIMPÓSIO NACIONAL DE PÓS-GRADUANDOS, 2. 2012, Rio de Janeiro. Anais... Rio de Janeiro: Unirio, 2012. v. 1. p. 121-168.

MEIRA, Silvio. Entrevista para Marcelo Tas (\#provoca). Disponível em: $<$ https://www.youtube.com/watch?v=O1wvWDv91GY>. Acessado em 08 dez. 2020.

PERKINS, Rosie; SPIRO, Neta; TYMOSZUK, Ula; WILLIAMON, Aaron. Loneliness and Social Isolation in Mental Health Network. Disponível em: $<$ https://performancescience.ac.uk/loneliness/>, 2020.

RAY, Sonia. Pedagogia da Performance Musical. Goiânia: Espaço Acadêmico, 2019.

RAY, Sonia. Série Performance Musical na Quarentena. 2020. Disponível em: $<$ www.facebook.com/soniaraybrasil $>$.

RAY, Sonia, ZANINI, Claudia e AGUIAR, Werner. (Orgs.) Concentração na Performance Musical: conceitos e Aplicações. Goiânia: Abrapem, 2020.

VILELA, Evaldo F. Formação na pós-graduação para o desenvolvimento científico, tecnológico e social do país. In: FERREIRA, L. (Coord.) Colóquio de Avaliação do Sistema de Pósgraduação da UFG. 2., Goiânia, 30 nov. 2020. Disponível em: $<$ https://www.youtube.com/watch?v=5iU160Q3Lpc $>$. 
